HIAS-E-58

\title{
The Role of Inflation Target Adjustment in Stabilization Policy
}

\author{
Yunjong Eo and Denny Lie \\ School of Economics, The University of Sydney, NSW, Australia
}

October 2017

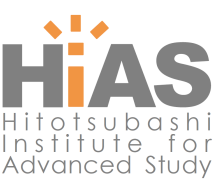

Hitotsubashi Institute for Advanced Study, Hitotsubashi University

2-1, Naka, Kunitachi, Tokyo 186-8601, Japan

tel:+81 425808604 http://hias.ad.hit-u.ac.jp/

HIAS discussion papers can be downloaded without charge from: http://hdl.handle.net/10086/27202

https://ideas.repec.org/s/hit/hiasdp.html

All rights reserved. 


\title{
The Role of Inflation Target Adjustment in Stabilization Policy*
}

\author{
Yunjong Eo ${ }^{\dagger} \quad$ Denny Lie ${ }^{\ddagger}$
}

This version: October 31, 2017

\begin{abstract}
How and under what circumstances can adjusting the inflation target serve as a stabilization-policy tool and contribute to welfare improvement? We answer these questions quantitatively with a standard New Keynesian model that includes cost-push type shocks which create a trade-off between inflation and output gap stabilization. We show that this trade-off leads to a non-trivial welfare cost under a standard Taylor rule, even with optimized policy coefficients. We then propose an additional policy tool of an inflation target rule and find that the optimal target needs to be adjusted in a persistent manner and in the opposite direction to the realization of a cost-push shock. The inflation target rule, combined with a Taylor rule, significantly reduces fluctuations in inflation originating from the cost-push shocks and mitigates the policy trade-off, resulting in a similar level of welfare to that associated with the Ramsey optimal policy. The welfare implications of the inflation target rule are more pronounced under a flatter Phillips curve.
\end{abstract}

JEL Classification: E12; E32; E58; E61;

Keywords: Welfare analysis; Monetary policy; Cost-push shocks; Medium-run inflation targeting; Flat Phillips curve;

\footnotetext{
${ }^{*}$ We thank James Bullard, Efrem Castelnuovo, Chris Edmond, Nicolas Groshenny, Joonyoung Hur, Jinill Kim, Mariano Kulish, Jae Won Lee, James Morley, Ed Nelson, Adrian Pagan, Bruce Preston, Jae W. Sim, Inhwan So, Willem Van Zandweghe, Toshiaki Watanabe, Yuzhe Zhang, and seminar and conference participants at Australian National University, Bank for International Settlements (Hong Kong), Bank of Korea, Korea University, Seoul National University, Sogang University, University of Adelaide, University of Melbourne, University of New South Wales, University of Queensland, AJRC and HIAS Joint Conference on Recent Issues in Finance and Macroeconomics, Hitotsubashi Summer Institute, KAEA-KEA International Conference, KAEA-KIF-KAFA Joint Conference, SNU Economics International Workshop, Asian Meeting of Econometric Society, Society for Nonlinear Dynamics and Econometrics Conference, Sydney Macroeconomics Workshop, Sydney University Min-Macroeconomics Workshop, and Workshop of the Australasian Macroeconomic Society for providing useful feedback. All errors are our own.

${ }^{\dagger}$ Corresponding author School of Economics, The University of Sydney, NSW, Australia; Email: yunjong.eo@sydney.edu.au

${ }^{\ddagger}$ School of Economics, The University of Sydney, NSW, Australia; Email: denny.lie@sydney.edu.au
} 


\section{Introduction}

The constancy of the central bank's inflation target has been one of the most enduring features in stabilization policy studies in the literature. These studies, whether they focus on positive or normative aspects of monetary policy, assume that the central bank stabilizes inflation around a constant, long-run target. From an empirical standpoint, however, several studies have documented that historically trend inflation has not been constant, see e.g. Kozicki and Tinsley (2003), Ireland (2007), and Cogley, Primiceri and Sargent (2010) for studies using the U.S. data. Interpreting time-varying trend inflation as adjustments in the central bank's implicit inflation target (or in the public's inflation-target expectations), this observation raises the question of whether there is an important role of such adjustments in a central bank's stabilization policy. How and under what circumstances are these adjustments warranted and possibly welfare-improving?

In this paper we investigate the role of inflation target adjustment in central banks' stabilization policy. We propose a scenario, as in Ireland (2007), where a central bank's inflation target is endogenous and depends on the state of the economy. In particular, the adjustment of the target is conditional on the realization of cost-push shocks. ${ }^{1}$ It is well known that cost-push shocks create a trade-off between inflation and output-gap stabilization. In this paper, we refer to this type of shocks as "cost-push shocks" but they potentially represent any shock that creates such a trade-off including variations in tax changes, changes in desired price markups by firms and wage markups by households, and oil price shocks. ${ }^{2}$

We show that adjustment of the inflation target, done properly, improves the central bank's policy-stabilization trade-off and can lead to a significant welfare improvement. In fact, despite the existence of the cost-push shocks, an interest-rate rule with an optimal inflation target adjustment is able to closely replicate the optimal Ramsey allocation. The extent of the improvement in the policy trade-off and the welfare improvement are above

\footnotetext{
${ }^{1}$ Ireland (2007) assumes that adjustment of the inflation target is conditional on the realization of costpush shocks as well as technology shocks and that the central bank stabilizes inflation around the time-varying target. Unlike Ireland (2007), however, we focus on the normative aspects of such adjustments, instead of the positive aspects.

${ }^{2}$ See Clarida, Galí and Gertler (1999); Erceg, Henderson and Levin (2000); Steinsson (2003); Smets and Wouters (2007); Natal (2012) for details. Blanchard and Galí (2007) call such a trade-off that the "divine coincidence" no longer holds with respect to these shocks.
} 
and beyond what is achievable in the conventional Taylor-type-rule policy environment with a constant, long-run inflation target.

The theoretical framework used for our analysis is a simple, microfounded New Keynesian model, along the lines of Rotemberg and Woodford (1997) and Steinsson (2003). The model has two standard market distortions: the relative-price distortion arising from nominal price rigidity and the average markup distortion due to firms' monopoly power. Aggregate fluctuations are driven by productivity, government spending, and cost-push (markup) shocks. Despite its simplicity, our model is rich enough to capture important implications of largerscale, empirically-driven models used to analyze the effects of monetary policy. Our main finding should hold true in those models, as long as there exists a trade-off between the two stabilization goals. The cost-push shock itself in our model can be treated as a familiar and convenient proxy for any shock that creates such a trade-off. ${ }^{3}$

We first show that in the face of cost-push shocks, it is not possible to achieve a similar welfare level to that associated with the Ramsey policy in an environment in which the monetary authority conducts policy through a standard Taylor-type rule with a constant inflation target. In particular, there still exists a non-trivial welfare cost, relative to the optimal Ramsey allocation, even under an optimized, implementable Taylor-type rule. Note that if only productivity and government spending shocks exist, there is no stabilization trade-off and the central bank can stabilize inflation and output at the same time. As shown by Schmitt-Grohé and Uribe (2007), in such an environment an optimized Taylor rule with a constant inflation target can mimic the Ramsey allocation quite well.

We then consider our proposed policy rule, which in addition to the nominal interest-rate adjustment using a Taylor rule, the monetary authority also adjusts the inflation target in response to a cost-push shock. We allow this adjustment to be temporal using a persistent inflation target that follows an autoregressive process. This implies that the nominal interest rate now responds to the inflation gap, defined by the difference between actual inflation and the medium-run inflation target, as well as the output gap.

The optimal target adjustment calls for changing the inflation target in the opposite

\footnotetext{
${ }^{3}$ Smets and Wouters (2007) find that cost-push shocks in their model, in the form of wage markup and price markup shocks, are largely responsible for inflation fluctuations in the postwar U.S. economy.
} 
direction in response to cost-push shocks. That is, we find that when there is a positive realization of a cost-push shock that raises inflation and leads to a negative output gap on impact, it is optimal for the monetary authority to decrease the inflation target. For any inflation rate above the initial target, a decreased target in turn leads to a bigger inflation gap compared to that in the standard Taylor rule and translates to a more aggressive response to the cost-push shock through a larger increase in the nominal interest rate. This policy combination leads to a significant welfare gain where the inflation variability is sufficiently reduced, without leading to too large increase in the variability of the output gap. Several studies, (e.g. Bomfim and Rudebusch (2000), Orphanides and Wilcox (2002), and Ireland (2007)), discuss the possibility that over the postwar period the Federal Reserve consistently translated adverse supply shocks (positive cost-push shocks) into more persistent inflation (a higher inflation target). ${ }^{4}$ Our finding implies that such an action is unwarranted and welfare-reducing.

We also note that this more-aggressive response to a realization of a cost-push shock in our target rule is not equivalent to simply increasing the inflation feedback coefficient in the Taylor-type rule from a welfare perspective. Even when the cost-push shock is the dominant driving process in the economy, it may not be optimal to increase the inflation feedback coefficient beyond a certain value because (i) the variability of the output gap is also a relevant determinant of welfare and (ii) the welfare loss from increasing the variation in the output gap may dominate the welfare gain from reducing the variation in inflation for too large values of the inflation coefficient in the Taylor-type rule. ${ }^{5}$ In particular, we show that even when we allow for a wider range of possible values of the Taylor-type rule feedback coefficients, it is not possible to achieve a similar welfare level to that associated with our optimized inflation target rule. Thus, the apparent improvement in a trade-off between inflation and output-gap stabilization is mainly attributable to the adjustment of the inflation target, and not because of any implementability restriction on the policy coefficients.

\footnotetext{
${ }^{4}$ Ireland (2007), however, finds that in the postwar U.S. economy a model with the endogenous movements in the inflation target is statistically indistinguishable from the exogenous inflation target model. Garnier, Mertens and Nelson (2015) obtain the same result using unobserved components models of trend inflation and the inflation gap in the U.S. economy.

${ }^{5}$ Woodford (2002) and Benigno and Woodford (2005) derive a welfare-based loss function and show that it depends on the variability of inflation and an output-gap measure. See also our discussion in Section 4.
} 
In addition, we consider an interest rate smoothing rule but it does not alter these policy implications and our findings are robust.

Our investigation also reveals that the extent of the welfare gain from the target adjustment depends on the slope of the Phillips curve. Various studies in the literature have documented a flattening of the Phillips curve for the U.S. and other advanced economies in recent years. ${ }^{6}$ One possible reason for this flattening is the increase in the degree of nominal rigidity, e.g. the probability of price fixity in the familiar Calvo (1983) model, as pointed by Blanchard (2016). A flatter Phillips curve makes the task of an inflation-targeting monetary authority more difficult, as inflation becomes less responsive to output-gap fluctuations. We show that the welfare gain from adjusting the inflation target is larger the flatter the slope of the Phillips curve is. Our proposed policy rule is thus even more appealing in such an environment.

Our finding is also potentially relevant to the current economic environment of low inflation rates under a flat Phillips curve, especially in advanced economies such as the U.S. and the Euro area. Blanchard (2016) argues that the flat Phillips curve raises serious challenges for monetary policy and may require very flexible inflation targeting. However, he does not propose how to implement flexible inflation targeting in practice and its welfare implication. If a negative realization of cost-push shocks or similar shocks contributes to the low-inflation environment, our finding suggests that an appropriate policy action is to just simply increase the medium-run inflation target. In addition, in a broader context, the finding in our paper can also serve as a justification for the practice of central banks in several countries of regularly readjusting and announcing their medium-run inflation targets. ${ }^{7}$ For example, in September 2016, the Bank of Japan introduced an inflation-overshooting commitment, under which it aims to exceed the inflation target of $2 \%$ and stay above the target in a stable manner. The Bank of Japan plans to make policy adjustments conditional on developments in economic activity and prices, as well as financial conditions toward achieving the inflation target of $2 \%$ in the long run. Though motivated by a different set of objectives, our finding

\footnotetext{
${ }^{6}$ The flattening of the Phillips curve in the U.S. and other advanced economies has been documented in various studies, e.g. Roberts et al. (2006), Kuttner and Robinson (2010), and Blanchard (2016).

${ }^{7} \mathrm{~A}$ non-exhaustive list of countries currently practising this policy includes Brazil, India, Indonesia, Nigeria, and South Korea.
} 
suggests that such a conditional adjustment might be welfare-improving.

The rest of this paper is organized as follows. Section 2 presents the model used for welfare analysis and its calibration. Section 3 introduces monetary policy rules and discusses a measure of household welfare. Section 4 conducts welfare analysis for several alternative policy rules, including our proposed policy of adjusting the inflation target. Section 5 presents sensitivity analysis involving the flattening of the Phillips curve and interest-rate smoothing. Section 6 concludes.

\section{Model and Calibration}

We consider a New Keynesian model along the lines of Rotemberg and Woodford (1997) and Steinsson (2003). The model consists of a representative household, a continuum of monopolistically-competitive firms producing differentiated varieties, and a monetary policy authority. ${ }^{8}$ Our model is closest to the cashless model in Schmitt-Grohé and Uribe (2007), although we abstract from capital accumulation and fiscal policy. ${ }^{9}$ Aggregate fluctuations are driven by three exogenous shocks: productivity, government purchase, and cost-push shocks. As we discussed, the inclusion of a cost-push shock is important because it creates a trade-off between inflation stabilization and output-gap stabilization, as in Steinsson (2003) and is consistent with empirical findings in the literature.

\subsection{Households}

The representative household maximizes a discounted sum of utilities of the form

$$
E_{t} \sum_{s=0}^{\infty} \beta^{s} \frac{\left[C_{t+s}\left(1-N_{t+s}\right)^{\gamma}\right]^{1-\sigma}-1}{1-\sigma},
$$

where $\beta \in(0,1)$ is the discount factor and $N_{t}$ denotes the household's labor supply. The consumption index $C_{t}$ is a Dixit-Stiglitz CES aggregator of differentiated consumption goods

\footnotetext{
${ }^{8}$ We abstract from fiscal policy dynamics by assuming that it follows a passive policy, in the sense of Leeper (1991).

${ }^{9}$ Schmitt-Grohé and Uribe (2007) find that monetary distortions are not quantitatively important in comparison to cashless economy and passive fiscal policy is optimal.
} 
or varieties, given by

$$
C_{t}=\left[\int_{0}^{1} C_{t}(i)^{1 /\left(1+\theta_{t}\right)} d i\right]^{1+\theta_{t}},
$$

where $\theta_{t}=1 /\left(\eta_{t}-1\right)$ is the firms' average markup at time $t$ and $\eta_{t}$ is the elasticity of substitution across varieties. The average markup shock follows

$$
\log \left(\theta_{t}\right)=\left(1-\rho_{\theta}\right) \log (\bar{\theta})+\rho_{\theta} \log \left(\theta_{t-1}\right)+\varepsilon_{\theta, t}
$$

with $\varepsilon_{\theta, t} \sim$ i.i.d.N $\left(0, \sigma_{\theta}^{2}\right)$.

Households earn the nominal wage rate $W_{t}$ by supplying $N_{t}$ and have access to a domestic bond market where the riskless one-period nominal government bonds, $B_{t}$, are traded. These bonds pay the gross interest rate $R_{t}$. Households also receive firms' profits, $\Pi_{t}^{\text {prof }}$, and government transfers or taxes, $T_{t}$. Thus, the one-period budget constraint is given by

$$
\int_{0}^{1} P_{t}(i) C_{t}(i) d i+B_{t} \leq R_{t-1} B_{t-1}+W_{t} N_{t}+\Pi_{t}^{\text {prof }}+T_{t}
$$

where $P_{t}(i)$ denotes the nominal price of variety $i$. Solving the household's problem and taking the first-order approximations of the resulting efficiency conditions around the longrun steady-state equilibrium yield a standard consumption Euler equation. Additional details on the households' optimality conditions are contained in the Appendix.

\section{$2.2 \quad$ Firms}

Each monopolistically-competitive firm produces a differentiated variety $i$ using labor with a production function

$$
Y_{t}(i)=z_{t} N_{t}(i)
$$

where $Y_{t}(i)$ is the production of good $i$ and $z_{t}$ is the aggregate productivity shock, which is assumed to follow a univariate autoregressive process

$$
\log \left(z_{t}\right)=\rho_{z} \log \left(z_{t-1}\right)+\varepsilon_{z, t}
$$

with $\varepsilon_{z, t} \sim$ i.i.d.N $\left(0, \sigma_{z}^{2}\right)$. 
Following Calvo (1983) and Yun (1996), only a $(1-\alpha) \in[0,1)$ fraction of firms are allowed to optimally adjust their prices at any given time period. We assume that firms that are not allowed to optimally reset their prices, with probability $\alpha$, simply index their prices to the steady-state gross inflation, $\bar{\Pi}$, which coincides with the monetary authority's time-invariant long-run inflation target. Thus, each optimizing firm $i$ chooses an identical optimal nominal price, $\tilde{P}_{t}(i)=\tilde{P}_{t}$, to maximize the expected discounted sum of profits

$$
\sum_{s=0}^{\infty} \alpha^{s} Q_{t, t+s}\left[\tilde{P}_{t}(i) \bar{\Pi}^{s} Y_{t+s}(i)-W_{t+s}(i) N_{t+s}(i)\right]
$$

where $Q_{t, t+s}=\beta^{s} \frac{\lambda_{t+s} / P_{t+s}}{\lambda_{t} / P_{t}}$ is the nominal stochastic discount factor between time $t$ and $t+s$ and $\lambda_{t}$ is the marginal utility of consumption.

The resulting first-order condition of the firms' optimal pricing problem and the associated aggregate-price level equation

$$
P_{t}=\left[(1-\alpha)\left(\tilde{P}_{t}\right)^{-\frac{1}{\theta_{t}}}+\alpha\left(\bar{\Pi} P_{t-1}\right)^{-\frac{1}{\theta_{t}}}\right]^{-\theta_{t}}
$$

make up the pricing block of the model. Taking the first-order approximations of these equations around the long-run steady-state equilibrium leads to the following New Keynesian Phillips curve (NKPC) equation (see Appendix for more details):

$$
\hat{\pi}_{t}=\beta E_{t} \hat{\pi}_{t+1}+\lambda \widehat{m c}_{t}+\hat{u}_{t}
$$

where $\lambda \equiv \frac{(1-\alpha \beta)(1-\alpha)}{\alpha}, \hat{u}_{t}$ is the reduced-form cost-push shock, which is a function of the shock to the average markup $\left(\hat{\theta}_{t}\right),{ }^{10}$ and $\widehat{m c}_{t}$ is $\log$ deviation of the real marginal cost. ${ }^{11}$ Alternatively, we can write the NKPC as a function of the output gap, $Y_{t} / Y_{t}^{*}$ :

$$
\hat{\pi}_{t}=\beta E_{t} \hat{\pi}_{t+1}+\kappa\left(\hat{Y}_{t}-\hat{Y}_{t}^{*}\right)+\hat{u}_{t}
$$

The coefficient on the output gap, i.e. the slope of the NKPC, is $\kappa=\left[(1-\bar{g})^{-1}+\frac{\bar{N}}{1-\bar{N}}\right] \lambda$,

\footnotetext{
${ }^{10}$ That is, $\hat{u}_{t} \equiv \frac{\left(1-\alpha \beta \rho_{\theta}\right)(1-\alpha)}{\alpha} \frac{1}{\bar{\eta}-1} \hat{\theta}_{t}$.

${ }^{11}$ See Clarida, Galí and Gertler (1999) for interpretation of the cost-push shock.
} 
with $\bar{g}$ and $\bar{N}$ denoting the steady-state government spending-output ratio and steady-state labor, respectively. Following Woodford (2003), we define potential output, $Y_{t}^{*}$, as the output level under the flexible-price equilibrium with constant average markup.

\subsection{The monetary authority and government}

The monetary authority follows a standard Taylor-type rule in which the authority engages in interest-rate smoothing and responds to deviations of inflation from an inflation target, as well as the output gap. We first present our benchmark rule in which the inflation target is defined by the long-run inflation target (i.e. the steady-state inflation rate). We then introduce our additional policy tool in which the inflation target is adjusted in response to cost-push shocks.

- Benchmark: the long-run inflation targeting

$$
\log \left(R_{t} / \bar{R}\right)=\phi_{\pi} \log \left(\Pi_{t} / \bar{\Pi}\right)+\phi_{Y} \log \left(Y_{t} / Y_{t}^{*}\right)
$$

where $\Pi_{t}$ is the quarterly rate of inflation and $\bar{R}$ is the steady state nominal interest rate.

Alternatively, as in Ireland (2007), we consider that instead of the long-run constant inflation target, the monetary authority reacts to the inflation deviation from the potentially time-varying, medium-run inflation target, which is adjusted in response to cost-push shocks. $^{12}$

- Proposed policy: the medium-run inflation targeting

$$
\begin{aligned}
\log \left(R_{t} / \bar{R}\right) & =\phi_{\pi} \log \left(\Pi_{t} / \Pi_{t}^{*}\right)+\phi_{Y} \log \left(Y_{t} / Y_{t}^{*}\right) \\
\log \left(\Pi_{t}^{*}\right) & =\log (\bar{\Pi})+\mu_{\pi^{*}} v_{\pi^{*}, t}
\end{aligned}
$$

where $v_{\pi^{*}, t}=\rho_{\pi^{*}} v_{\pi^{*}, t-1}+\varepsilon_{\theta, t}$ and $\varepsilon_{\theta, t}$ is the innovation in the markup shock, as previously defined in (3). The medium-run inflation targeting (MRIT) in (12) shows that the medium-run

\footnotetext{
${ }^{12}$ Ireland (2007) also considers the inflation target's response to a technology shock, but we do not take it into account in our policy framework because this shock does not create the trade-off between inflation and the output gap stabilization.
} 
inflation target, $\pi_{t}^{*}=\log \left(\Pi_{t}^{*}\right)$, is the sum of two distinct components. The first component, $\bar{\pi}=\log (\bar{\Pi})$, is the long-run inflation target. The second component $\mu_{\pi^{*}} v_{\pi^{*}, t}$, that constitutes the endogenous adjustment of the target, i.e. its evolution is directly controlled by the monetary authority. The dynamics of the adjustment is controlled through the coefficients $\mu_{\pi^{*}}$ and $\rho_{\pi^{*}}$ - the former can be interpreted as the instantaneous response to the markup shock, while the latter can be thought as the smoothness parameter, i.e. how the monetary authority spreads the target adjustment across multiple periods.

The government issues one-period nominal risk-free bonds, makes transfers, imposes taxes, and faces an exogenous expenditure stream, $G_{t}$. Thus, the one-period government budget constraint is given by

$$
B_{t}=R_{t-1} B_{t-1}+P_{t} G_{t}+T_{t}
$$

Government spending is assumed to follow a univariate autoregressive process of the form

$$
\log \left(G_{t} / \bar{G}\right)=\rho_{g} \log \left(G_{t-1} / \bar{G}\right)+\varepsilon_{g, t}
$$

with $\varepsilon_{g, t} \sim$ i.i.d.N $\left(0, \sigma_{g}^{2}\right)$.

\subsection{Competitive equilibrium}

The stationary equilibrium in our economy is characterized by prices and quantities that satisfy the optimality conditions of the households and firms, in addition to a monetary policy rule and the aggregate market clearing condition for goods, labor, and assets. The aggregate employment is given by the sum of employment across firms:

$$
N_{t}=\int_{0}^{1} N_{t}(i) d i
$$

We assume that the government minimizes the cost of producing $G_{t}$. Thus, the public good demand for each intermediate good $i$ is given by $G_{t}(i)=\left(\frac{P_{t}(i)}{P_{t}}\right)^{-\frac{1+\theta_{t}}{\theta_{t}}} G_{t}$. Thus, aggregate demand is given by

$$
Y_{t}=C_{t}+G_{t}
$$


Table 1: Model Calibration

\begin{tabular}{lll}
\hline Parameter & Value & Description \\
\hline$\sigma$ & 2 & preference parameter \\
$\gamma$ & 3.613 & preference parameter \\
$\beta$ & $1.04^{-1 / 4}$ & quarterly discount rate \\
$\bar{\theta}$ & 0.25 & steady-state price markup 25\%; price elasticity of demand 5 \\
$\bar{G}$ & 0.055 & steady-state level of government spending \\
$\alpha$ & 0.80 & share of firms that cannot change their price each period \\
$\bar{\Pi}$ & 1 & steady-state gross inflation or long-run inflation target \\
$\rho_{z}$ & 0.95 & persistence of productivity shock \\
$\rho_{\theta}$ & 0.60 & persistence of cost-push shock \\
$\rho_{g}$ & 0.50 & persistence of government spending \\
$\sigma_{z}$ & 0.007 & standard deviation of productivity innovation \\
$\sigma_{\theta}$ & 0.130 & standard deviation of cost-push innovation \\
$\sigma_{g}$ & 0.160 & standard deviation of government spending innovation \\
\hline
\end{tabular}

where $Y_{t}(i)=\left(\frac{P_{t}(i)}{P_{t}}\right)^{-\frac{1+\theta_{t}}{\theta_{t}}} Y_{t}$ and $Y_{t}(i)=C_{t}(i)+G_{t}(i)$. We provide the complete equilibrium equations in the Appendix.

\subsection{Calibration}

We calibrate our model based on the values of structural parameters from Schmitt-Grohé and Uribe (2007) and present these values in Table 1. The choice of $\gamma$ implies that the steady-state labor $\bar{N}$ is 0.23 and the steady-state labor-to-leisure ratio $(\bar{N} /(1-\bar{N}))$ of 0.29 . $\bar{\eta}=5$ corresponds to the steady-state average price markup of $25 \%$. The choice of $\bar{G}=0.055$ implies that steady-state ratio of government spending to output $(\bar{g} \equiv \bar{G} / \bar{Y})$ is $24 \%$. The steady-state gross inflation, or the long-run inflation target, is $\bar{\Pi}=1$. This zero net inflation coincides with the (Ramsey) optimal steady-state inflation in our model. ${ }^{13}$

A key parameter for the welfare analysis in the next section is the Calvo parameter, which determines the slope of the NKPC. The Calvo parameter $\alpha$, which denotes the probability that a firm cannot change its price optimally in any given period. Following Schmitt-Grohé

\footnotetext{
${ }^{13}$ The model contains two market distortions: the relative-price distortion due to sticky prices and average markup distortion arising from firms' monopoly power. As shown in various studies, e.g. Benigno and Woodford (2005), Khan, King and Wolman (2003), King and Wolman (1999), and Woodford (2002), zero inflation minimizes both distortions and constitutes the optimal policy.
} 
and Uribe (2007), we set the Calvo parameter to $\alpha=0.8 .{ }^{14}$ The average duration of price fixity is about 5 quarters for $\alpha=0.8$. In addition, this calibrated Calvo parameter corresponds to the NKPC slope of $\lambda=0.052$ in (8) when marginal cost is used as the driving process for inflation and the NKPC slope of $\kappa=0.084$ in (9) when the output gap is used. Following the business cycle literature, the persistence parameter $\rho_{z}$ and the standard deviation $\sigma_{z}$ for the productivity shock are taken to be 0.95 and 0.007 , respectively. The remaining parameters for the structural shock processes, $\rho_{g}, \rho_{\theta}, \sigma_{g}$, and $\sigma_{\theta}$ are set to closely match the standard deviations of inflation and output for the postwar U.S. economy from 1947:Q1 to 2008:Q4. ${ }^{15}$ To obtain these values, we assume the standard Taylor-rule coefficients of $\phi_{\pi}=1.5$ and $\phi_{Y}=0.5$.

\section{Monetary policy and welfare}

We conduct welfare analysis mainly for three different policies in comparison to the Ramsey optimal policy:

(i) Taylor rule: the Taylor rule $\left(\phi_{\pi}=1.5, \phi_{Y}=0.5\right)$ without the MRIT;

(ii) Taylor-MRIT rule: the optimal MRIT conditional on the Taylor rule;

(iii) Optimized Taylor rule: the optimal implementable Taylor rule without the MRIT.

The Taylor rule (i) sets the policy parameters to $\phi_{\pi}=1.5$ and $\phi_{y}=0.5$ in (10), which are quite close to those reported in the literature for the post-1984 U.S. economy. The optimized Taylor-MRIT rule (ii) entails a monetary authority that adjusts the medium-run inflation target by choosing the parameter values $\mu_{\pi^{*}}$ and $\rho_{\pi^{*}}$ in (12) to maximize welfare of the representative household, conditional on the Taylor rule coefficients $\phi_{\pi}=1.5$ and $\phi_{y}=0.5$. Under the optimized Taylor rule (iii), the monetary authority simply chooses the welfare-maximizing values of $\phi_{\pi}$ and $\phi_{y}$ in (10), without adjusting the medium-run inflation

\footnotetext{
${ }^{14}$ Estimates in the literature of the Calvo parameter range from 0.72 to 0.83 for the postwar U.S. economy. For example, they are found to be 0.83 in Levin et al. (2005), 0.79 for a DSGE-VECM model, 0.83 for a DSGE model in Del Negro et al. (2007), and 0.72 in Herbst and Schorfheide (2014). The average of these estimates is 0.79 , which is quite close to our calibrated parameter value of $\alpha=0.8$.

${ }^{15}$ We use CPI inflation and detrended output.
} 
target. Formally, for policy rules (ii) and (iii), we search for the relevant policy parameters, $\left\{\mu_{\pi^{*}}, \rho_{\pi^{*}}\right\}$ in (ii) and $\left\{\phi_{\pi}, \phi_{y}\right\}$ in (iii), that maximize the unconditional expectation of lifetime utility, $E\left(V_{t}\right)$, where

$$
V_{t}=E_{t} \sum_{s=0}^{\infty} \beta^{s} U\left(C_{t+s}, N_{t+s}\right)
$$

and $E$ denotes the unconditional expectation operator. ${ }^{16}$ For the welfare measure in (17) to adequately capture the effect of uncertainties, we compute the second-order accurate solution to the equilibrium policy functions, including for $V_{t}{ }^{17}$

Following Schmitt-Grohé and Uribe (2007), in searching for the optimal values of the Taylor parameters, we restrict $\phi_{\pi} \in(0,3]$ and $\phi_{y} \in(0,3]$ for the optimized Taylor rule (iii). Schmitt-Grohé and Uribe (2007) argue that policy coefficients larger than 3 (or negative) would be difficult for policymakers to communicate to the public. We also rule out those parameter values that yield an indeterminate equilibrium. In addition, we restrict $\left|\mu_{\pi^{*}}\right|<$ 0.10 and $\rho_{\pi^{*}} \in[0,1)$ when searching for the Taylor-MRIT rule (ii). The restriction on the value of $\mu_{\pi^{*}}$ is somewhat ad-hoc. However, for the same reason as with regard to the Taylortype rule parameters, an excessively large value of $\mu_{\pi^{*}}$ may undermine the credibility of the monetary authority in delivering the stated objectives. ${ }^{18}$

\subsection{The Ramsey policy}

To evaluate and compare various policies above we use the time-invariant (timeless perspective) stochastic Ramsey optimal policy as the benchmark. Under the Ramsey policy, the policy authority acts benevolently and searches for the allocation that maximizes the welfare of the representative agent. Following the standard approach in the literature, we abstract from any specific form of the policy rule and search instead for the optimal Ramsey alloca-

\footnotetext{
${ }^{16}$ Our results continue to hold if, instead, the policy parameters used are those that maximize the conditional expectation, $V_{0}$, i.e. conditional on the initial state of the economy being the nonstochastic steady state.

${ }^{17}$ See Schmitt-Grohé and Uribe (2004) for a discussion on why a second-order approximation to the equilibrium solution is needed for an accurate welfare computation. Also see Johnston, King and Lie (2014) for the detail of the solution method that we use.

${ }^{18}$ We sidestep this possible credibility issue in this paper and leave it for future research.
} 
tion. ${ }^{19}$ In addition, as in the competitive equilibrium, the Ramsey equilibrium is solved up to a second-order approximation. The Appendix contains additional details on the derivation and computation of the Ramsey policy. Armed with the Ramsey policy, we can then calculate the conditional and unconditional welfare costs of any alternative policy relative to the Ramsey policy, which is described in the following section.

\subsection{Welfare cost measure}

As in Schmitt-Grohé and Uribe (2007), we define the welfare cost of implementing an alternative policy as the fraction of consumption that the representative household would be willing to give up under the benchmark Ramsey policy environment to be equally well off, as under the alternative policy environment. Specifically, let $\left\{C_{t}^{r}, N_{t}^{r}\right\}$ and $\left\{C_{t}^{a}, N_{t}^{a}\right\}$ be the state-contingent plans for consumption and labor under the Ramsey policy and under the alternative policy, respectively. The conditional welfare cost, $\lambda_{c}$, is implicit in the expression

$$
E_{0} \sum_{t=0}^{\infty} \beta^{t} U\left(C_{t}^{a}, N_{t}^{a}\right)=E_{0} \sum_{t=0}^{\infty} \beta^{t} U\left(\left(1-\lambda_{c}\right) C_{t}^{r}, N_{t}^{r}\right) .
$$

The expectation operator above makes clear that the welfare cost is conditional on the initial state at time $t=0$, which we assume to be the deterministic steady state under the Ramsey policy. The deterministic steady state under the alternative policy is assumed to be identical to that under the Ramsey policy. Similarly, the unconditional welfare cost, $\lambda_{u}$, can be obtained from

$$
E \sum_{t=0}^{\infty} \beta^{t} U\left(C_{t}^{a}, N_{t}^{a}\right)=E \sum_{t=0}^{\infty} \beta^{t} U\left(\left(1-\lambda_{u}\right) C_{t}^{r}, N_{t}^{r}\right)
$$

Here, $E$ is the unconditional expectation operator. For the specific form of the utility function and the calibrated parameters in Table 1, we can then calculate the second-order approximations to $\lambda_{c}$ and $\lambda_{u}$ for any alternative policy rule. ${ }^{20}$

\footnotetext{
${ }^{19}$ See, for example, Erceg, Henderson and Levin (2000), Khan, King and Wolman (2003), Lie (2015), and Schmitt-Grohé and Uribe (2007).

${ }^{20}$ In fact, since our utility function in (1) is identical to that in Schmitt-Grohé and Uribe (2007), we obtain the same expressions for both $\lambda_{c}$ and $\lambda_{u}$ - see equations (38) and (39) in the expanded version of their paper, Schmitt-Grohé and Uribe (2006).
} 
Table 2: Welfare cost of various policies

\begin{tabular}{llccrrrrrr}
\hline & \multicolumn{4}{c}{ Policy Parameters } & & Conditional & Unconditional \\
& & $\phi_{\pi}$ & $\phi_{Y}$ & \multicolumn{1}{c}{$\mu_{\pi^{*}}$} & $\rho_{\pi^{*}}$ & $\lambda_{c} \times 100$ & $\begin{array}{r}\text { Welfare Cost } \\
\lambda_{u} \times 100\end{array}$ & $\sigma\left(\pi_{t}-\bar{\pi}\right)$ & $\sigma\left(\hat{y}_{t}-\hat{y}_{t}^{*}\right)$ \\
\hline (i) Taylor rule & 1.50 & 0.50 & - & - & 0.507 & 0.531 & 4.015 & 8.819 \\
(ii) Taylor-MRIT rule & 1.50 & 0.50 & -0.0731 & 0.77 & 0.186 & 0.192 & 2.186 & 13.558 \\
(iii) Optimized Taylor rule & 3.00 & 0.38 & - & - & 0.310 & 0.321 & 3.123 & 10.170 \\
(iv) Optimized Taylor-MRIT rule & 3.00 & 2.22 & -0.10 & 0.77 & 0.044 & 0.044 & 1.556 & 10.727 \\
\hline
\end{tabular}

Note: The conditional and unconditional welfare costs are in terms of percent per annum consumption loss relative to the Ramsey allocation. The standard deviation $\sigma($.$) is expressed in percent per year. For the Taylor-MRIT rule (ii), we search for$ $\mu_{\pi^{*}}$ and $\rho_{\pi^{*}}$ that maximize the unconditional welfare, while fixing $\phi_{\pi}=1.5$ and $\phi_{Y}=0.5$. For the optimized Taylor-MRIT rule, we search for optimal $\phi_{\pi}, \phi_{Y}$, and $\mu_{\pi^{*}}$, while fixing $\rho_{\pi^{*}}=0.77$. We restrict $\left|\phi_{\pi}\right|<3,\left|\phi_{Y}\right|<3$, and $\left|\mu_{\pi^{*}}\right|<0.10$ when searching for optimized coefficients.

\section{Optimized interest rate rules}

\subsection{Welfare under the medium-run inflation targeting}

We evaluate various policies discussed in the previous section. Table 2 reports the conditional and unconditional welfare cost measures, $\lambda_{c}$ and $\lambda_{u}$, in comparison to the Ramsey policy. We find that the Taylor rule (i) yields conditional and unconditional welfare costs of $0.507 \%$ and $0.531 \%$ per annum of consumption relative to the Ramsey policy. To express the cost in monetary value, we could use U.S. annual personal consumption expenditure per capita as a proxy for real consumption. In 2015 , the figure is $\$ 38,183$ in current U.S. dollars. Hence, a $0.531 \%$ consumption cost is equivalent to $\$ 204$ per annum per capita. This is in fact quite a sizable business-cycle cost and is comparable to the finding in Schmitt-Grohé and Uribe (2007).

We next study the implication of our proposed policy, the Taylor-MRIT rule (ii), where the monetary authority can additionally adjust the medium-run inflation target in response to cost-push shocks over time. Our numerical search yields the optimal MRIT coefficients of $\mu_{\pi^{*}}=-0.073$ and $\rho_{\pi^{*}}=0.77$. The negative value of $\mu_{\pi^{*}}$ implies that when inflation increases because of a positive realization of cost-push shock, the monetary authority decreases the medium-run inflation target. All else equal, this policy action leads to a bigger inflation gap $\left(\Pi_{t} / \Pi_{t}^{*}\right)$ compared to the Taylor rule (i) in (10) without the MRIT adjustment. It follows that a bigger inflation gap translates to a more aggressive response to the cost-push shock 
through a larger increase in the nominal interest rate, as evident from the Taylor-MRIT rule in (11). In addition, the fact that the optimized MRIT rule features substantial inertia means that the monetary authority needs to react persistently to the cost-push shocks given a realization of the cost-push shock. This smoothing adjustment can be explained by the persistent effect of the cost-push shocks on inflation.

We find that the welfare gain from the MRIT adjustment is significant. The TaylorMRIT rule (ii) yields conditional and unconditional welfare costs of $0.186 \%$ and $0.192 \%$ of consumption relative to the Ramsey policy. When compared to the welfare costs associated with the Taylor rule (i), the welfare gain implies that agents would be willing to give up more than 32 basis points of their consumption per annum stream under the Taylor-MRIT rule (ii) to be as well off as under the Taylor rule (i). Or alternatively, using the unconditional cost measure, we can say that the welfare gain from adopting the Taylor-MRIT rule policy over the Taylor rule policy is $64 \% .^{21}$

To better understand the reason for the welfare gain we compute the standard deviations of inflation and the output gap. The standard deviations of inflation and the output gap for the Taylor rule (i) are $4.02 \%$ and $8.82 \%$, respectively, while they are $2.19 \%$ and $13.56 \%$ for the optimized Taylor-MRIT (ii). ${ }^{22}$ These calculations show that the MRIT, which allows for more aggressive reaction to inflation due to the cost-push shocks, reduces inflation volatility by a factor of two, but only increases the volatility of the output gap by about $65 \%$. This, coupled with the fact that inflation variation carries a much higher weight in the utility-based welfare measure relative to the output-gap variation, is the source of the significant welfare gain. ${ }^{23}$

We next investigate whether the optimized Taylor rule (iii) can produce a comparable welfare gain as the Taylor-MRIT rule (ii). As in Schmitt-Grohé and Uribe (2007), we focus on an implementable rule and limit $\left|\phi_{\pi}, \phi_{y}\right| \leq 3$. We find that the best implementable Taylortype rule requires an aggressive response to inflation and a somewhat muted response to the output gap fluctuation. The optimized Taylor rule needs the policy coefficients of $\phi_{\pi}=3$,

\footnotetext{
${ }^{21}$ We find the welfare gain based on $(0.53-0.19) / 0.53=64$.

${ }^{22}$ The standard deviations are expressed in percent per year.

${ }^{23}$ This much-higher weight on inflation variation can be seen by deriving the welfare-theoretic loss function, as in Woodford (2003) and Benigno and Woodford (2005). We also illustrate this in Section 5.1 in the paper.
} 
which is the largest allowable value, and $\phi_{Y}=0.38$. Note that this inflation coefficient of $\phi_{\pi}=3$ in the optimized Taylor rule is consistent with that in Schmitt-Grohé and Uribe (2007). This finding about taking the largest value for the inflation coefficient reflects the fact that inflation variation is an important element in welfare. In contrast to their finding, however, we find that the optimal $\phi_{Y}$ is not zero. This discrepancy comes from two important differences between our economy and the one considered in Schmitt-Grohé and Uribe (2007): the presence of the cost-push shock in our model; and the fact that we define the output gap measure in the policy rule as the deviation of output from its flexible-price equilibrium level, instead of from the constant steady-state level. Since the welfare-relevant output gap is the measure of output gap that we use, the optimal $\phi_{Y}$ may no longer be zero. ${ }^{24}$ The existence of the policy stabilization trade-off between inflation and output-gap due to the presence of the cost-push shock is responsible for the low optimal value of $\phi_{Y}$ relative to $\phi_{\pi}$ - here, the trade-off is resolved in favor of inflation stabilization. If there is no costpush shock, productivity and government spending shocks are the only source of aggregate fluctuations as in Schmitt-Grohé and Uribe (2007) and there is no trade-off between the two stabilization goals. Then it does not matter whether the monetary authority responds strongly to inflation or output-gap fluctuations. ${ }^{25}$

In terms of the welfare implication, the optimized Taylor-rule (iii) still yields nonnegligible welfare costs of $0.310 \%$ and $0.321 \%$, respectively. Thus, relative to the TaylorMRIT rule (ii), the welfare gain from the optimized Taylor-rule (iii) over the Taylor rule (i) is smaller. The standard deviation of inflation in the optimized Taylor-rule is about $50 \%$ larger compared to that in the Taylor-MRIT rule, while the standard deviation of the output gap is only about $25 \%$ smaller. Hence, it appears that adjustment of the medium-run inflation target leads to a better trade-off between inflation and output-gap variations. We investigate this important finding in the next section.

\footnotetext{
${ }^{24}$ See Woodford (2003) for additional details on the welfare-relevant output gap measure.

${ }^{25}$ In fact, without the cost-push shock $\left(\sigma_{\theta}=0\right)$, we find that the optimized Taylor-type rule comprises $\phi_{\pi}=\phi_{Y}=3$.
} 


\subsection{The improvement in inflation-output gap trade-off}

The extent of the inflation-output trade-off is an important consideration when conducting monetary policy. The greater the trade-off is, the more difficulty the monetary authority faces in stabilizing inflation and output-gap fluctuations. We argue that the ability of the monetary authority to adjust the medium-run inflation target in the face of cost-push shocks leads to a more favorable inflation-output trade-off. This improvement in the trade-off leads to welfare gain, above and beyond what is possible in the standard Taylor-rule policy. This source of inflation-output trade-off improvement, to the best of our knowledge, is a new result in the literature. ${ }^{26}$

We first show this improvement by searching jointly for optimal $\phi_{\pi}, \phi_{Y}$, and $\mu_{\pi^{*}}$. The coefficient $\rho_{\pi^{*}}$ is fixed at 0.77 , which is the optimal value under the Taylor-MRIT policy (ii). ${ }^{27}$ We call this policy rule the optimized Taylor-MRIT rule (iv). The last row of Table 2 reports the numerical results. Compared to the Taylor-MRIT rule (ii) in which we fix the Taylor coefficients at $\phi_{\pi}=1.5$ and $\phi_{y}=0.5$, the welfare costs are now much smaller at $0.04 \%$ of consumption per capita per annum. The optimized Taylor-MRIT rule thus appears to be able to replicate the Ramsey allocation quite well. This policy calls for the maximum allowable value for $\phi_{\pi}=3$, a much higher value of $\phi_{Y}=2.22$ in comparison to the output-gap coefficient of 0.38 in the optimized Taylor rule (iii), and the minimum allowable value for $\mu_{\theta}=-0.10$. Thus, in the face of a positive realization of the cost-push shock, the monetary authority chooses to respond more aggressively to output gap fluctuations. It is optimal to do so because the monetary authority can now respond to the increase in inflation by further reducing the medium-run inflation target (a more negative $\mu_{\pi^{*}}$ ). Without an improved inflation-output trade-off by adopting the MRIT rule, reacting strongly to the output gap with $\phi_{Y}=2.22$ would not be optimal, as shown for the Taylor-MRIT rule (iii). Note that, in the standard environment with a fixed inflation target, a more aggressive response to inflation fluctuations originating from cost-push shocks (i.e. a higher value of $\phi_{\pi}$ or a lower value of $\phi_{Y}$ ) would be optimal because inflation fluctuations are much more important than

\footnotetext{
${ }^{26}$ Other sources have been identified in the literature. For example, Clarida, Galí and Gertler (1999) show that adopting a precommitment policy leads to an improved inflation variability-output variability compared to a discretionary policy.

${ }^{27}$ The results do not materially change when we also numerically search for optimal $\rho_{\pi^{*}}$.
} 
output gap fluctuations in the utility-based welfare measure. Finally, consistent with the welfare cost results, the standard deviation of inflation is now only $1.56 \%$, while the standard deviation of the output gap is roughly the same as in the optimized Taylor rule (iii).

The results above raise the question whether the allocation under the optimized TaylorMRIT policy (iv) can be achieved solely with an "unconstrained" Taylor rule, i.e. when we remove the upper limit of $\phi_{\pi}$ and $\phi_{Y}$ coefficients. If so, the improvement in the inflation-output trade-off under the MRIT policy is just a mirage, arising because of the implementability restriction. To investigate this, we look at the implications of various values of $\phi_{\pi}$ and $\phi_{Y}$ for the unconditional welfare cost. ${ }^{28}$

Figure 1 plots unconditional welfare costs for various combinations of policy coefficients under the Taylor-type rule without the MRIT. The top panel of Figure 1 depicts the welfare cost when we vary $\phi_{\pi}$, while fixing $\phi_{Y}=0.38$ (the optimal value in the optimized TaylorMRIT policy (iii)). The panel shows that the unrestricted optimal value of $\phi_{\pi}$ is 18 above this value, the welfare cost starts increasing again. Intuitively, a too-high value of $\phi_{\pi}$ means that the monetary authority responds too aggressively to inflation fluctuations and too timidly to output-gap fluctuations given the trade-off originating from cost-push shocks. The middle and bottom panels of Figure 1 depict the welfare cost when we vary $\phi_{Y}$, given a value of $\phi_{\pi}$. When the value of $\phi_{\pi}$ is fixed to 3 , the optimal $\phi_{Y}$ value is 0.38 . The welfare cost is higher when $0<\phi_{Y}<0.38$ since the monetary authority's response to output-gap fluctuations is too timid. On the contrary, when $\phi_{Y}>0.38$ she responds too aggressively. When $\phi_{\pi}$ is fixed at a higher value of 50 (bottom panel), the optimal value of $\phi_{Y}$ becomes higher. ${ }^{29}$ All in all, the results presented in Figure 1 imply that the jointly optimized values of $\phi_{\pi}$ and $\phi_{Y}$ should be finite and relatively small. More importantly, at least for the range of coefficient values considered in Figure 1, the welfare costs appear to be higher than $0.044 \%$, which is the welfare cost from the optimized Taylor-MRIT (vi): the combination of the optimized Taylor-type rule and the MRIT. Thus, the improvement in the inflation-output trade-off under the MRIT policy is clearly evident.

\footnotetext{
${ }^{28}$ The results are unaltered when the conditional cost measure is used instead.

${ }^{29}$ This makes sense since in the presence of a policy stabilization trade-off between inflation and outputgap, a more aggressive response to inflation fluctuations calls for a more aggressive response to output-gap fluctuations, albeit at different degrees.
} 
Figure 1: Unconditional welfare cost under the Taylor-type rule without the MRIT
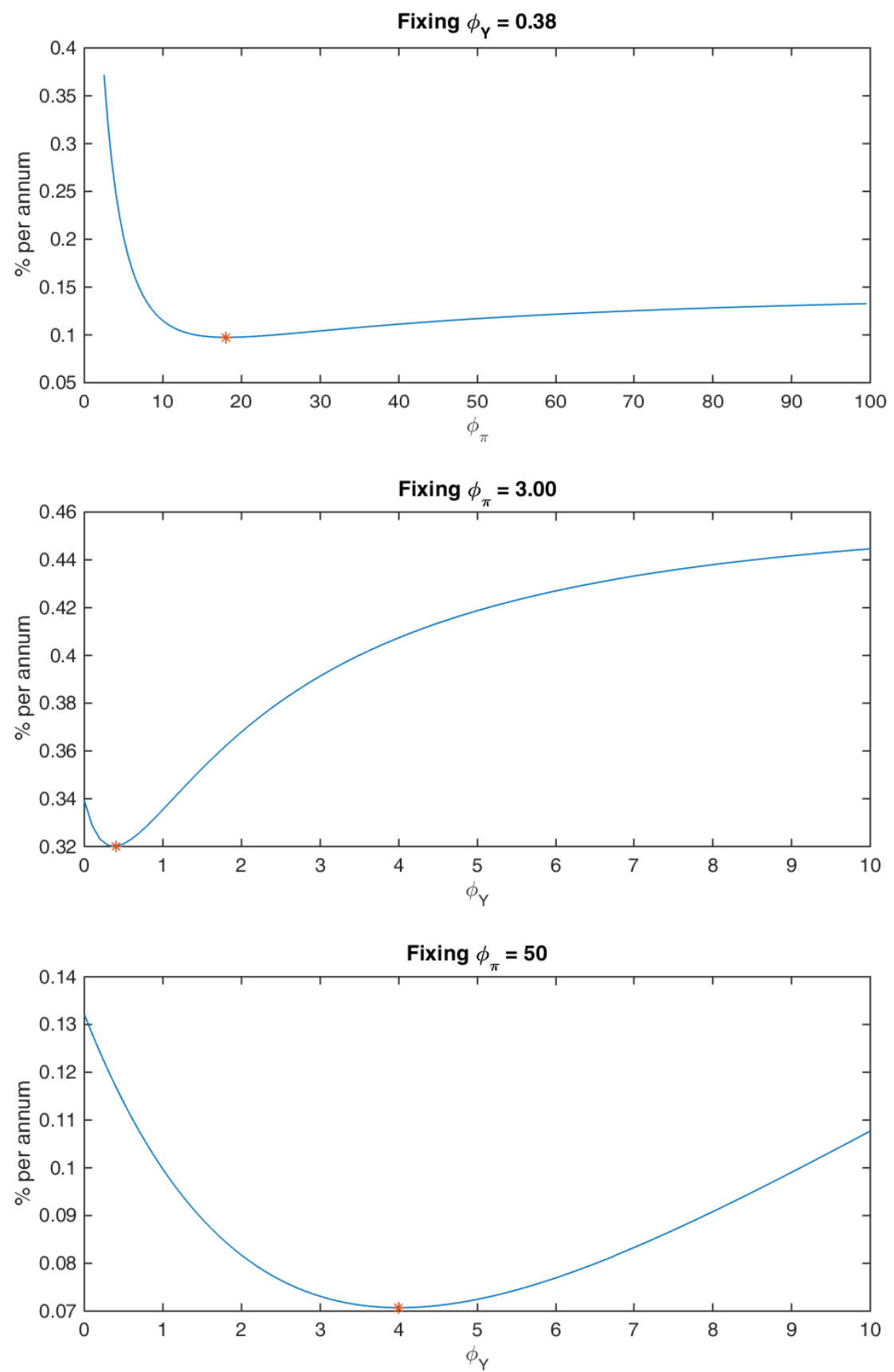

Note: We fix one of policy coefficients, $\phi_{\pi}$ and $\phi_{Y}$, and vary the other parameter. In addition, we set $\phi_{R}=0$ for all cases. 
Figure 2: Unconditional welfare cost under the Taylor-type rule for various values of $\phi_{\pi}$ and $\phi_{Y}\left(\phi_{R}=0\right.$ for all cases $)$
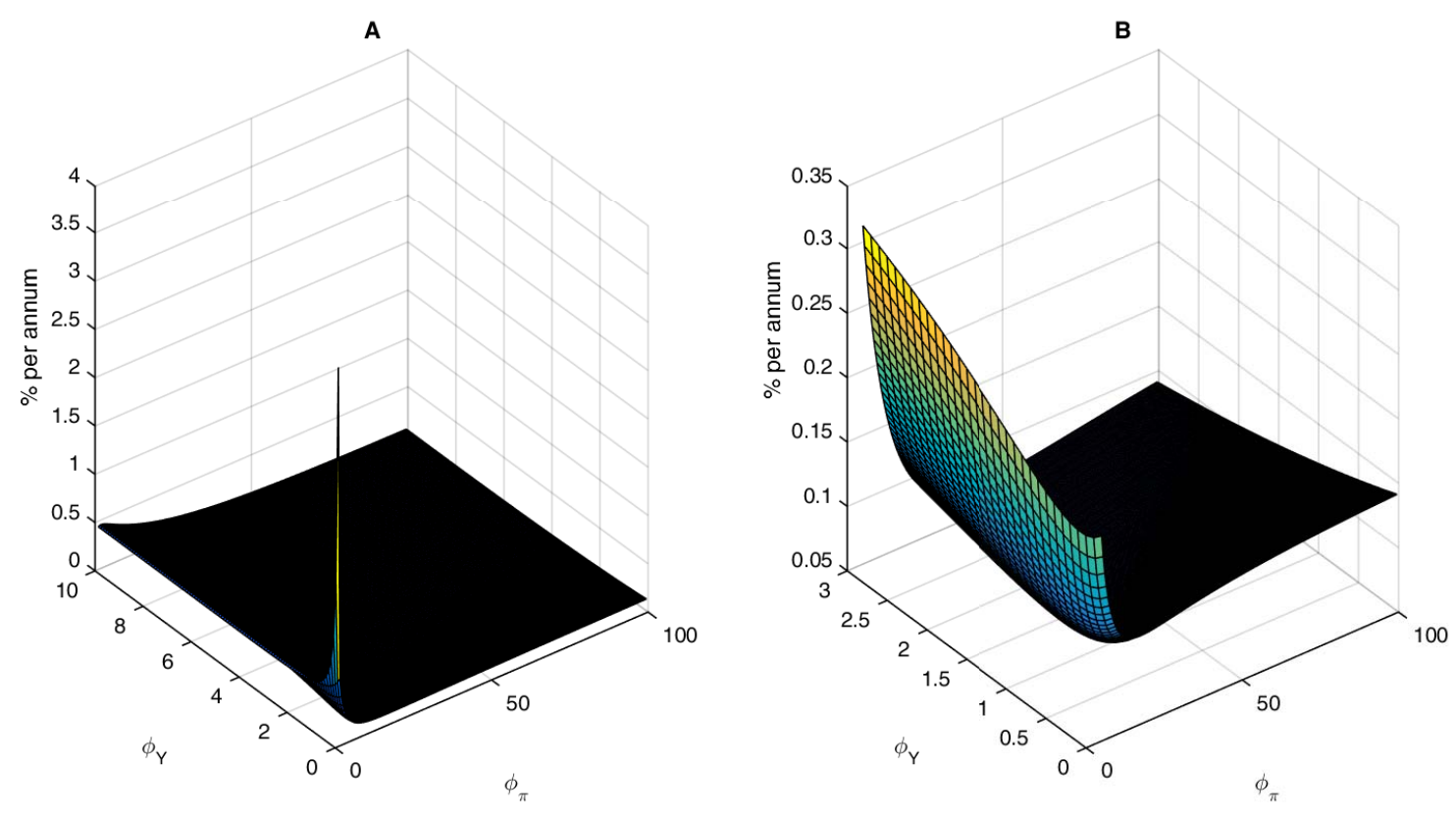

Figure 2 offers more comprehensive, three-dimensional pictures of the unconditional welfare costs when we jointly vary $\phi_{\pi}$ and $\phi_{Y}$. Panel A considers a wider range of values, $\phi_{\pi} \in(1,100]$ and $\phi_{Y} \in(0,10]$, while panel B limits $\phi_{Y} \in(0,3]$ for a clearer view. Again, the two panels show that the joint optimal values of $\phi_{\pi}$ and $\phi_{Y}$ are finite. The smallest unconditional welfare cost is at $\lambda_{u}=0.07 \%$, which is achieved at $\phi_{\pi}=100$ and $\phi_{Y}=8.5{ }^{30}$ We note that this combination of optimal parameter values is not unique. For example, one can always achieve a similar optimal allocation by increasing both $\phi_{\pi}$ and $\phi_{Y}$ appropriately. Despite this, it is not possible to reduce the welfare cost much beyond $\lambda_{u}=0.07 \%$. This indicates that the improved inflation-output trade-off under the MRIT policy is not due to the implementability constraint. Treating the optimized Taylor-MRIT policy (iv) in Table 2 as the best, the monetary authority could further reduce the welfare cost by $43 \%$ using the MRIT. ${ }^{31}$ In addition, we search over the policy coefficients under the Taylor-type rule, which

\footnotetext{
${ }^{30}$ Unlike the result in Schmitt-Grohé and Uribe (2007), it is not possible in our environment to fully replicate the Ramsey allocation (i.e. zero welfare cost) due to the existence of the cost-push shock.

${ }^{31}$ That is, $(0.07-0.04) / 0.07=0.43$.
} 
Figure 3: Impulse response to a $1 \%$ cost-push shock
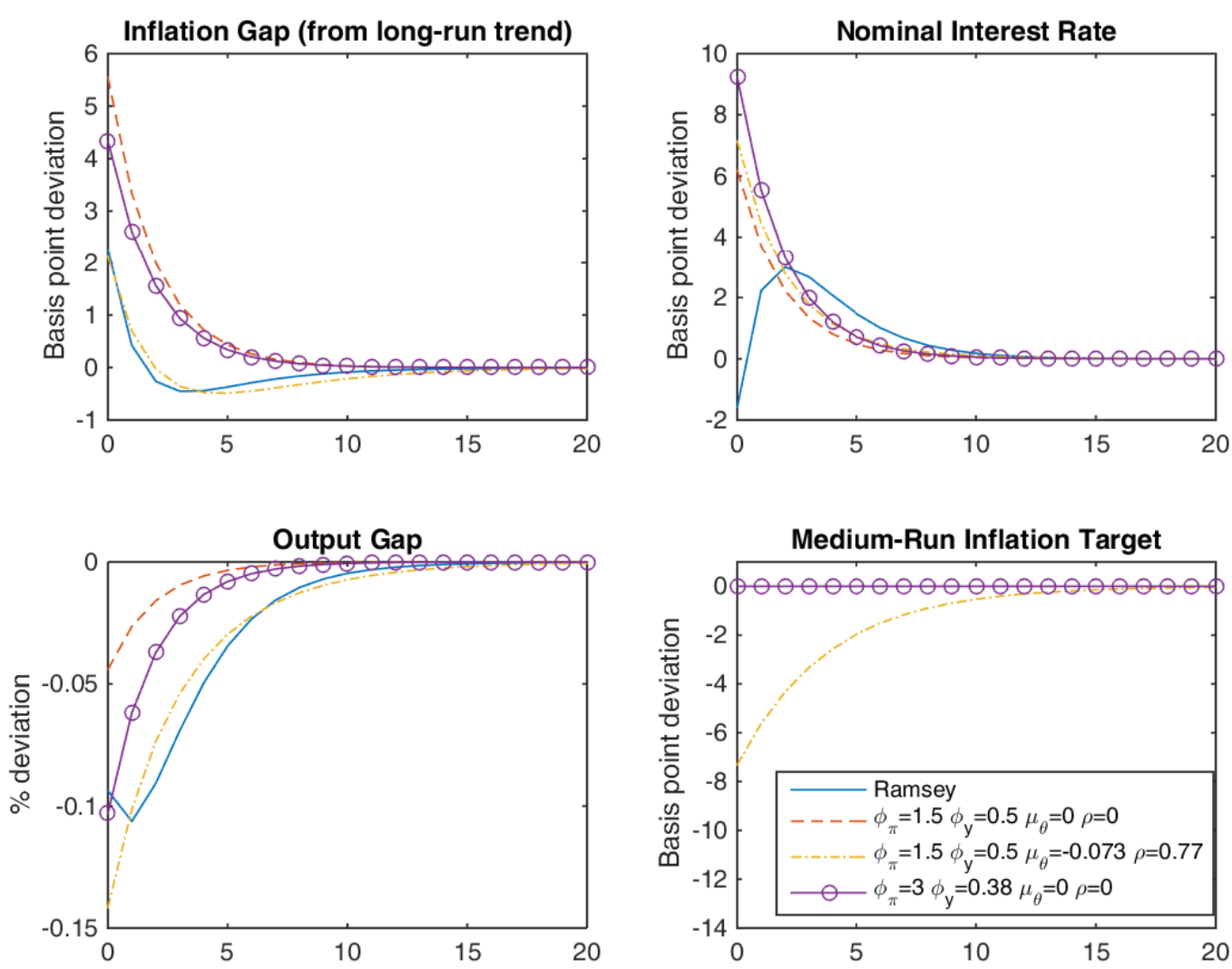

Note: The evolution of the average markup cost-push shock is given by $\log \left(\theta_{t}\right)=\left(1-\rho_{\theta}\right) \log (\bar{\theta})+\rho_{\theta} \log \left(\theta_{t-1}\right)+\varepsilon_{\theta, t}$, where $\rho_{\theta}=0.6$. We calibrate the size of the innovation, $\varepsilon_{\theta, t}$, so that $\theta_{t}$ increases by one percent on impact relative to the steady-state value.

would lead to the same welfare level associated with the Taylor-MRIT rule. We find that multiple pairs of the policy coefficients - for example, $\left(\phi_{\pi}, \phi_{Y}\right)=(5.51,0.00),(22.01,8.20)$ - can achieve the welfare level, but they require implausibly high inflation coefficients. ${ }^{32}$ The inflation coefficient of $\phi_{\pi}=5.51$ is the lower bound.

The inflation-output trade-off improvement under the MRIT policy is also visible from impulse response functions, as depicted in Figure 3. We plot the impulse responses of inflation, the nominal interest rate, the output gap, and the medium-run inflation target to

\footnotetext{
${ }^{32}$ The reason we find the multiple pairs of the coefficients is that the welfare level is not the optimum under the unconstrained optimized Taylor rule.
} 
one percent increase in the cost-push shock for the alternative policies in Table 2. Under the Taylor rule (i), inflation increases with the biggest magnitude in comparison to other policy rules and then dies out slowly. The optimized Taylor rule (iii) with $\phi_{\pi}=3$ and $\phi_{Y}=0.38$ produces only marginally smaller inflation fluctuations than the Taylor rule (top left panel) - this, however, is enough to make the welfare costs smaller in the optimized Taylor rule, despite larger output gap fluctuations (bottom left panel).

Under the Taylor-MRIT rule (ii), the impulse response function of inflation almost perfectly matches that under the Ramsey policy. This is a reflection of the fact that the welfare cost of this policy is close to that under the Ramsey policy, shown in Table 2. The output-gap fluctuations under this policy are larger than under the other policies considered, although they mimic the Ramsey dynamics quite well in latter periods. But again, compared to inflation fluctuations, output-gap fluctuations matter much less in the welfare function.

The Taylor-type rules restrict the dynamics of the nominal interest rates as a function of inflation and the output gap and make the impulse response functions die out smoothly over time. However, the Ramsey policy optimally determines the nominal interest rates without any restrictions and sets negative nominal interest rates in the first period as shown in Figure 3. This flexibility helps generate a smaller fluctuation in the output gap in the first period and achieve a lower welfare cost in comparison to the Taylor-MRIT rule while two policy rules produce very similar impulse response functions for inflation.

We note that under the benchmark Ramsey policy, complete price stability is not optimal. This is true as long as the weight on the output-gap stabilization in the welfare function is not zero and there exists a trade-off between inflation stabilization and output-gap stabilization, due to the existence of cost-push shocks.

To measure the improvement in the inflation-output trade-off by adopting the TaylorMRIT rule (ii) over the optimized Taylor rule (iii), we compute the cumulative deviations of inflation and the output gap based on the impulse responses in Figure 3. In the optimized Taylor rule, the ratio of cumulative inflation deviations to output-gap deviations is 0.42 . The ratio is 0.12 in the Taylor-MRIT rule. This means that to close the output gap by $1 \%$ in response to a cost-push shock, the monetary authority has to increase the inflation gap on average by $0.42 \%$ under the optimized Taylor rule, but only by $0.12 \%$ when she is allowed 
to optimally adjust the medium-run inflation target. By this measure, the inflation-output trade-off is improved by more than twofold.

\section{The slope of the Phillips curve and interest-rate smooth- ing}

We conduct two additional analyses on the welfare implications of the NKPC slope and interest rate smoothing.

First, we establish the relationship between the welfare gains from our proposed MRIT and the NKPC slope, which is governed by the Calvo parameter. As we discuss below, the Calvo parameter is an important parameter for welfare analysis as it affects the propagation of cost-push shocks and the relative weights of various stabilization goals in the welfare function.

Second, we introduce interest-rate smoothing in the Taylor rule. We investigate if the welfare gain from "interest-rate" smoothing is significant and if this alternative specification affects the magnitude of the welfare gain from our proposed MRIT we found in the previous section.

\subsection{The flattening (steepening) of the NKPC}

\subsubsection{Illustration with a prototype model}

To illustrate the implications of a flatter (or a steeper) NKPC for monetary policy in the presence of cost-push shocks, we consider a prototypical three-equation New Keynesian model. Despite its simplicity, the model structure is rich enough to understand the propagation mechanism of the cost-push shock and its welfare implication for the conduct of monetary policy. The log-linearized version of the prototype New Keynesian model yields the following representation for the New Keynesian Phillips curve, the IS curve, and the monetary policy 
rule:

$$
\begin{aligned}
\pi_{t} & =\beta E_{t} \pi_{t+1}+\kappa y_{t}+\mu_{t} \\
y_{t} & =E_{t} y_{t+1}-\left(R_{t}-E_{t} \pi_{t+1}\right) \\
R_{t} & =\phi_{\pi}\left(\pi_{t}-\pi^{*}\right)+\phi_{y} y_{t}
\end{aligned}
$$

where $\pi_{t}$ is inflation, $y_{t}$ is the output gap, $R_{t}$ is the short-term nominal interest rate, $\pi^{*}$ is the (long-run) inflation target, and $\mu_{t}$ is a cost-push shock.

Now, we consider the policy response to cost-push shocks in this model. A positive realization of these shocks creates an upsurge in inflation and a negative output gap. Iterating the NKPC in (18) forward indicates that inflation is a function of the expected discounted sum of the future output gap $y_{t}$ and cost-push shock $\mu_{t}$ :

$$
\pi_{t}=E_{t} \sum_{s=0}^{\infty} \beta^{s}\left(\kappa y_{t+s}+\mu_{t+s}\right)
$$

The strength of the link between inflation and the output gap is directly governed by the slope parameter $\kappa$ in (21). When $\kappa$ is small (i.e. the NKPC is flat), the output gap hardly drives inflation dynamics and the variation in inflation would be mostly explained by the cost-push shocks, $\mu_{t}$. In addition, the IS curve in (19) shows that the output gap is a function of the sum of expected future real interest rates by iterating the IS curve forward:

$$
y_{t}=-E_{t} \sum_{s=0}^{\infty}\left(R_{t+s}-\pi_{t+s+1}\right)
$$

Thus, the monetary authority can influence the output gap by manipulating the real rate indirectly through adjustments of the short-term nominal interest rate given sticky prices using the Taylor-type policy rule in (20). In response to the increase in inflation, the monetary authority raises the nominal interest rate by amounts greater than increases in inflation so that the real interest rate goes up. ${ }^{33}$ The IS curve in (22) implies that the increase in the real interest rate lowers the output gap further and in turn, inflation is reduced through the

\footnotetext{
${ }^{33}$ The increase in the nominal interest rate is due to $\phi_{\pi}>1$. More precisely, we consider the determinate regions of the parameter space for $\phi_{y}, \phi_{\pi}$, and $\kappa$. For more details, see Bullard and Mitra (2002).
} 
NKPC relationship.

However, as pointed out in the cost-push channel for inflation, a flat NKPC implies that the effect of output gap on inflation fluctuations is limited so that monetary policy is less effective in controlling inflation in the face of cost-push shocks. Thus, the effect of cost-push shocks on inflation would last longer. It is also notable that the decrease of the output gap arising from the positive cost-push shocks lowers the nominal interest rate in the opposite direction compared to the effect of inflation gap on the adjustment of the nominal interest rates, as noted in the monetary policy rule (20). In the presence of the trade-off between inflation stabilization and output-gap stabilization, e.g. due to the existence of the cost-push shock, this offsetting effect weakens the monetary authority's reaction to inflation fluctuations and presents an additional difficulty in conducting monetary policy

A flat NKPC has also the important welfare implication that the inflation variation becomes enormously more important than the output gap fluctuation. Following Rotemberg and Woodford (1997, 1999), Woodford (2003), and Steinsson (2003), the utility-based welfare loss function in period $t$ can be represented by

$$
L_{t}=\pi_{t}^{2}+\frac{\kappa}{\eta} y_{t}^{2}
$$

where $\eta$ is the steady-state elasticity of substitutions between intermediate-good varieties. Woodford (2003) shows that the weight on the output gap $\kappa / \eta$ in the loss function (23) is small using the conventional calibrated parameters so that inflation plays a primary role in determining household welfare. In addition, we can see that as the NKPC becomes flatter (i.e. $\kappa \rightarrow 0$ ), the inflation variation becomes even more important because the weight on the output gap in the loss function gets smaller.

In short, the flattening of the NKPC results in the difficulty in improving household welfare through monetary policy from three perspectives: (i) the fraction of inflation variation due to cost-push shocks becomes increasingly substantial; (ii) controlling inflation through monetary policy becomes much harder conditional on the cost-push shocks; and (iii) inflation becomes completely dominant over the output gap in determining household welfare. 
Table 3: Welfare cost of various policies with alternative Calvo parameter values

\begin{tabular}{|c|c|c|c|c|c|c|c|c|}
\hline & \multicolumn{4}{|c|}{ Policy Parameters } & \multirow{2}{*}{$\begin{array}{r}\text { Conditional } \\
\text { Welfare Cost } \\
\lambda_{c} \times 100\end{array}$} & \multirow{2}{*}{$\begin{array}{r}\text { Unconditional } \\
\text { Welfare Cost } \\
\lambda_{u} \times 100\end{array}$} & \multirow[t]{2}{*}{$\sigma\left(\pi_{t}-\bar{\pi}\right)$} & \multirow[t]{2}{*}{$\sigma\left(\hat{y}_{t}-\hat{y}_{t}^{*}\right)$} \\
\hline & $\phi_{\pi}$ & $\phi_{Y}$ & $\mu_{\theta}$ & $\rho_{v_{\theta}}$ & & & & \\
\hline$\alpha=0.85$ & & & & & & & & \\
\hline (i) Taylor rule & 1.50 & 0.50 & - & - & 0.783 & 0.832 & 4.020 & 9.346 \\
\hline $\begin{array}{l}\text { (ii) Taylor-MRIT rule } \\
\alpha=0.70\end{array}$ & 1.50 & 0.50 & -0.0641 & 0.79 & 0.171 & 0.176 & 2.013 & 18.031 \\
\hline (i) Taylor rule & 1.50 & 0.50 & - & - & 0.311 & 0.321 & 4.452 & 7.466 \\
\hline (ii) Taylor-MRIT rule & 1.50 & 0.50 & -0.0817 & 0.73 & 0.215 & 0.221 & 3.414 & 8.993 \\
\hline
\end{tabular}

Note: We conduct welfare analysis for policies (i) and (ii) as in Table 2, but with different values of the NKPC slope, $\alpha=0.85$ and $\alpha=0.70$. For each $\alpha$ case, the standard deviation of the innovation in the markup shock $\varepsilon_{\theta, t}$ is rescaled so that the variance of the reduced-form cost-push shock $\hat{u}_{t}$ in the NKPC remains the same as in the benchmark case $(\alpha=0.80)-$ all other parameter values are as in Table 1 . The welfare costs are relative to the Ramsey allocation in each respective $\alpha$ case, i.e. we resolve the Ramsey policy equilibrium for each case. We restrict $\left|\phi_{\pi}\right|<3,\left|\phi_{Y}\right|<3$, and $\left|\mu_{\theta}\right|<0.10$ when searching for optimized coefficients. The standard deviation of inflation and the output gap rate is expressed in percent per year.

\subsubsection{The slope of the Phillips curve and welfare costs}

The flattening of the NKPC since the mid-1980s has been widely documented in the literature. ${ }^{34}$ The NKPC slope in $(8)$ is given by $\lambda=(1-\alpha \beta)(1-\alpha) / \alpha$ and is mainly governed by the Calvo parameter $\alpha$. To establish the relationship between the NKPC slope and the effectiveness of monetary policy, we set $\alpha=0.70$ for a steep slope and $\alpha=0.85$ for a flat slope. These parameter values are closely matched to the pre- and post-1980 U.S. economies. For example, Bhattarai, Lee and Park (2016) find that the Calvo parameter is estimated to be 0.67 for 1960:Q1 to 1979:Q2 and 0.84 for 1982:Q4 to 2008:Q2. These Calvo parameter values correspond to 0.166 for the pre-1980 period and 0.032 for the post-1980 period under the marginal-cost-based NKPC in (8). In addition, the slope $\kappa$ in the output-gap-based NKPC in (9) is equal to 0.268 and 0.052 for the same two sub-periods. Thus, the slope of the NKPC appears to have flattened substantially, with the slope coefficient reduced to about a fifth of its pre-1980 period size.

The discussion using a prototype model in the previous section implies that a flatter NKPC due to a higher Calvo parameter should lead to a higher welfare cost under a standard Taylor rule but a higher welfare gain from adopting the MRIT policy - that is, the improvement in the inflation-output trade-off should be larger. Or conversely, we should

\footnotetext{
${ }^{34}$ See our discussion in introduction and references therein for more details.
} 
see a relatively smaller welfare gain from adopting the MRIT under a steeper NKPC. We conduct the same welfare analysis as in Section 4 with different slopes of the NKPC. In each case, we rescale the standard deviation of the innovation in the markup shock $\varepsilon_{\theta, t}$ so that the variance of the reduced-form cost-push shock $\hat{u}_{t}$ in the NKPC in (9) remains the same as in the benchmark case of $\alpha=0.8$. We do this to focus on the impact of the change in the slope of the NKPC on the effectiveness of monetary policy rules.

Table 3 reports the welfare-cost results under the Taylor rule (i) and the Taylor-MRIT rule (ii) for $\alpha=0.85$ and $\alpha=0.70$ as in Table 2. When the NKPC is flat (i.e. $\alpha=0.85$ ), the standard Taylor rule produces the conditional and unconditional welfare cost of $0.783 \%$ and $0.832 \%$, respectively. The larger welfare costs compared to those for $\alpha=0.70$ are to be expected, since as discussed above, the flatter NKPC due to a high Calvo parameter makes it relatively harder for the monetary authority to stabilize inflation. However, the monetary authority can do better by adjusting the medium-run inflation target in the face of a cost-push shock when the Phillips curve becomes flatter. Here, despite a marginally smaller (absolute) value of $\mu_{\theta}$ for $\alpha=0.85$, the welfare gain, however, is significantly bigger in comparison to the case of $\alpha=0.70$. We calculate the welfare gain using the unconditional cost criterion by $\left(\lambda_{u, i}-\lambda_{u, i i}\right) / \lambda_{u, i}$ where $\lambda_{u, i}$ and $\lambda_{u, i i}$ are the unconditional welfare costs for the Taylor rule (i) and the Taylor-MRIT rule (ii), respectively. We find that the welfare gain from adopting the Taylor-MRIT rule over the Taylor rule increases from 0.31 for $\alpha=0.70$ to 0.79 for $\alpha=0.85$. In the benchmark case for $\alpha=0.8$, reported in Table 2 , the corresponding welfare gain is 0.64 .

Thus, the results in Table 3 confirm that the flattening of the NKPC, as evidenced in the literature, makes our proposed policy rule of adjusting the medium-run inflation target under an inflation-output trade-off even more appealing. When considering the current economic environment of low inflation rates under a flat Phillips curve in many developed economies, our main findings imply that the monetary authority should increase the inflation target in such an environment. 
Table 4: Welfare cost of various policies with interest-rate smoothing

\begin{tabular}{|c|c|c|c|c|c|c|c|c|}
\hline & \multicolumn{4}{|c|}{ Policy Parameters } & \multirow{2}{*}{$\begin{array}{r}\text { Conditional } \\
\text { Welfare Cost } \\
\lambda_{c} \times 100 \\
\end{array}$} & \multirow{2}{*}{$\begin{array}{r}\text { Unconditional } \\
\text { Welfare Cost } \\
\lambda_{u} \times 100\end{array}$} & \multirow{2}{*}{$\sigma\left(\pi_{t}-\bar{\pi}\right)$} & \multirow{2}{*}{$\sigma\left(\hat{y}_{t}-\hat{y}_{t}^{*}\right)$} \\
\hline & $\phi_{\pi}$ & $\phi_{Y}$ & $\mu_{\theta}$ & $\rho_{v_{\theta}}$ & & & & \\
\hline (i) Taylor rule & 1.50 & 0.50 & - & - & 0.404 & 0.423 & 3.611 & 9.505 \\
\hline (ii) Taylor-MRIT rule & 1.50 & 0.50 & -0.0767 & 0.73 & 0.146 & 0.150 & 1.889 & 13.790 \\
\hline (iii)Optimized Taylor rule & 3.00 & 0.13 & - & - & 0.239 & 0.245 & 2.572 & 12.417 \\
\hline (iv) Optimized Taylor-MRIT rule & 3.00 & 1.95 & -0.10 & 0.73 & 0.050 & 0.050 & 1.458 & 11.595 \\
\hline
\end{tabular}

Note: All the respective cases above replicate the results reported in Table 2, but with the Taylor rule now given by $\log \left(R_{t} / \bar{R}\right)=\phi_{R} \log \left(R_{t-1} / \bar{R}\right)+\left(1-\phi_{R}\right)\left(\phi_{\pi} \log \left(\Pi_{t} / \bar{\Pi}\right)+\phi_{Y} \log \left(Y_{t} / Y_{t}^{*}\right)\right)$, with the smoothing parameter $\phi_{R}$ set to 0.65. We restrict $\left|\phi_{\pi}\right|<3,\left|\phi_{Y}\right|<3$, and $\left|\mu_{\theta}\right|<0.10$ when searching for optimized coefficients. The standard deviation of inflation and the output gap rate is expressed in percent per year.

\section{$5.2 \quad$ Interest-rate smoothing}

We now introduce interest-rate smoothing and examine if our findings based on a simple Taylor-type rule are robust to this alternative specification. The interest-rate smoothing rule becomes

$$
\log \left(R_{t} / \bar{R}\right)=\phi_{R} \log \left(R_{t-1} / \bar{R}\right)+\left(1-\phi_{R}\right)\left(\phi_{\pi} \log \left(\Pi_{t} / \bar{\Pi}\right)+\phi_{Y} \log \left(Y_{t} / Y_{t}^{*}\right)\right)
$$

where we set $\phi_{R}=0.65$ and all other parameters are as in Table 1.

Table 4 reports the implication of introducing interest-rate smoothing in the Taylor-type rule. The result under interest-rate smoothing with the Taylor rule coefficients (policy (i)) implies that there is a gain from smoothing the nominal interest rate movements. Both the conditional and unconditional welfare costs are now about 0.1 percentage points smaller compared to those without smoothing reported in Table 2. However, the results under policies (ii)-(iv) confirm that the interest rate smoothing does not alter our main findings qualitatively and they are robust. Even under interest-rate smoothing, the monetary authority can achieve a non-trivial improvement under the inflation-output trade-off by optimally adjusting the medium-run inflation target in the face of a cost-push shock. The improved trade-off, in turn, leads to a significant welfare gain. 


\section{Conclusion}

In this paper we show that there is an important role of inflation target adjustment in central bank's stabilization policy. Our findings demonstrate that it is welfare-improving to adjust the medium-run inflation target in the opposite direction in response to a realization of cost-push shocks. That is, the target needs to be increased when negative cost-push shocks contribute to a low-inflation environment. This additional policy tool improves the policy stabilization trade-off and leads to significant welfare improvement that is not achievable in a conventional interest-feedback rule with a long-run, constant inflation target. The welfare implications are more pronounced under a flatter Phillips curve.

Our proposed scenario is relevant to the current U.S. low-inflation environment since the recovery from the Great Recession. The inflation rates have been persistently lower than the Fed's 2\% target since the target was introduced in 2012 and the economy appears to approach the long-run unemployment rate in 2017. This also implies that the Phillips curve appears to be flatter than in the past as pointed out by Blanchard (2016). If inflation continues to undershoot the $2 \%$ target while job growth remains strong and the unemployment rate is below the long-run unemployment rate, low inflation and low unemployment can be largely attributable to negative "cost-push" shocks such as changes in price and wage markups and oil price shocks. If this is the case, our findings suggest that it may be prudent for the Federal Reserve to increase its target, at least in the medium run. 


\section{References}

Benigno, Pierpaolo, and Michael Woodford. 2005. "Inflation stabilization and welfare: The case of a distorted steady state." Journal of the European Economic Association, 3(6): 1185-1236.

Bhattarai, Saroj, Jae Won Lee, and Woong Yong Park. 2016. "Policy regimes, policy shifts, and US business cycles." Review of Economics and Statistics, 98(5): 968-983.

Blanchard, Olivier. 2016. "Where to from Here? The Phillips Curve: Back to the'60s?" The American Economic Review, 106(5): 31-34.

Blanchard, Olivier, and Jordi Galí. 2007. "Real wage rigidities and the New Keynesian model." Journal of money, credit and banking, 39(s1): 35-65.

Bomfim, Antulio N, and Glenn D Rudebusch. 2000. "Opportunistic and deliberate disinflation under imperfect credibility." Journal of Money, Credit and Banking, 707-721.

Bullard, James, and Kaushik Mitra. 2002. "Learning about monetary policy rules." Journal of Monetary Economics, 49(6): 1105-1129.

Calvo, Guillermo A. 1983. "Staggered prices in a utility-maximizing framework." Journal of Monetary Economics, 12(3): 383-398.

Clarida, Richard, Jordi Galí, and Mark Gertler. 1999. "The Science of Monetary Policy: A New Keynesian Perspective." Journal of Economic Literature, 37: 1661-1707.

Cogley, Timothy, Giorgio E Primiceri, and Thomas J Sargent. 2010. "Inflation-gap persistence in the US." American Economic Journal: Macroeconomics, 2(1): 43-69.

Del Negro, Marco, Frank Schorfheide, Frank Smets, and Rafael Wouters. 2007. "On the fit of new Keynesian models." Journal of Business 85 Economic Statistics, 25(2): 123-143.

Erceg, Christopher J, Dale W Henderson, and Andrew T Levin. 2000. "Optimal monetary policy with staggered wage and price contracts." Journal of monetary Economics, 46(2): 281-313. 
Garnier, Christine, Elmar Mertens, and Edward Nelson. 2015. "Trend Inflation in Advanced Economies." International Journal of Central Banking, 11(S1): 65-136.

Herbst, Edward, and Frank Schorfheide. 2014. "Sequential Monte Carlo sampling for DSGE models." Journal of Applied Econometrics, 29(7): 1073-1098.

Ireland, Peter N. 2007. "Changes in the Federal Reserve's inflation target: Causes and consequences." Journal of Money, Credit and Banking, 39(8): 1851-1882.

Johnston, Michael K, Robert G King, and Denny Lie. 2014. "Straightforward approximate stochastic equilibria for nonlinear Rational Expectations models." CAMA Working Paper.

Khan, Aubhik, Robert G King, and Alexander L Wolman. 2003. "Optimal monetary policy." The Review of Economic Studies, 70(4): 825-860.

King, Robert, and Alexander L Wolman. 1999. "What should the Monetary Authority do when Prices are sticky?" In Monetary policy rules. , ed. John B. Taylor, 349-398. University of Chicago Press.

Kozicki, Sharon, and Peter A Tinsley. 2003. "Alternative sources of the lag dynamics of inflation." In Price Adjustment and Monetary Policy: Proceedings of a Conference Held by the Bank of Canada, November 2002. 863-904.

Kuttner, Ken, and Tim Robinson. 2010. "Understanding the flattening Phillips curve." The North American Journal of Economics and Finance, 21(2): 110-125.

Leeper, Eric M. 1991. "Equilibria under active and passive monetary and fiscal policies." Journal of Monetary Economics, 27(1): 129-147.

Levin, Andrew T, Alexei Onatski, John C Williams, and Noah Williams. 2005. "Monetary policy under uncertainty in micro-founded macroeconometric models." NBER macroeconomics annual, 20: 229-287.

Lie, Denny. 2015. "State-Dependant Pricing and Optimal Monetary Policy." Working paper. Marcet, Albert, and Ramon Marimon. 2011. "Recursive contracts." Working paper. 
Natal, Jean. 2012. "Monetary policy response to oil price shocks." Journal of Money, Credit and Banking, 44(1): 53-101.

Orphanides, Athanasios, and David W Wilcox. 2002. "The opportunistic approach to disinflation." International finance, 5(1): 47-71.

Roberts, John M, et al. 2006. "Monetary Policy and Inflation Dynamics." International Journal of Central Banking, 2(3).

Rotemberg, Julio, and Michael Woodford. 1997. "An optimization-based econometric framework for the evaluation of monetary policy." In NBER Macroeconomics Annual 1997, Volume 12. 297-361. MIT Press.

Rotemberg, Julio J, and Michael Woodford. 1999. "Interest rate rules in an estimated sticky price model." In Monetary policy rules. 57-126. University of Chicago Press.

Schmitt-Grohé, Stephanie, and Martın Uribe. 2004. "Solving dynamic general equilibrium models using a second-order approximation to the policy function." Journal of Economic Dynamics and Control, 28(4): 755-775.

Schmitt-Grohé, Stephanie, and Martín Uribe. 2006. "Optimal Simple and Implementable Monetary and Fiscal Rules: Expanded Version." National Bureau of Economic Research WP 12402.

Schmitt-Grohé, Stephanie, and Martin Uribe. 2007. "Optimal simple and implementable monetary and fiscal rules." Journal of Monetary Economics, 54(6): 1702-1725.

Smets, Frank, and Rafael Wouters. 2007. "Shocks and frictions in US business cycles: A Bayesian DSGE approach." The American Economic Review, 97(3): 586-606.

Steinsson, Jon. 2003. "Optimal monetary policy in an economy with inflation persistence." Journal of Monetary Economics, 50(7): 1425-1456.

Woodford, Michael. 2002. "Inflation stabilization and welfare." Contributions in Macroeconomics, 2(1). 
Woodford, Michael. 2003. Interest and prices: Foundations of a theory of monetary policy. Princeton university press.

Yun, Tack. 1996. "Nominal price rigidity, money supply endogeneity, and business cycles." Journal of Monetary Economics, 37(2): 345-370. 


\section{A Appendix}

This appendix describes additional details of the model and computational issues.

Our model consists of a representative household, a continuum of monopolisticallycompetitive firms producing differentiated varieties, and a monetary policy authority. Our adopted model is based upon the model used in Schmitt-Grohé and Uribe (2007), although we abstract from monetary distortions, capital accumulation, and fiscal policy.

\section{Households}

Households choose the state-contingent consumption, $C_{t}$, labor service, $N_{t}$, and one-period discount bond, $B_{t}$, to maximize the lifetime utility,

$$
E_{t} \sum_{s=0}^{\infty} \beta^{s} \frac{\left[C_{t+s}\left(1-N_{t+s}\right)^{\gamma}\right]^{1-\sigma}-1}{1-\sigma}
$$

subject to the per-period nominal budget constraint

$$
P_{t} C_{t}+B_{t} \leq R_{t-1} B_{t-1}+W_{t} N_{t}+\Pi_{t}^{p r o f}+T_{t}
$$

or, in real terms,

$$
C_{t}+b_{t} \leq R_{t-1} \frac{b_{t-1}}{\Pi_{t}}+w_{t} N_{t}+\frac{\Pi_{t}^{\text {prof }}}{P_{t}}+\tau_{t}
$$

$b_{t} \equiv B_{t} / P_{t}$ is real bond, $R_{t}$ is the nominal interest rate, $w_{t}$ is the real wage, $\frac{\Pi_{t}^{\text {prof }}}{P_{t}}$ is the proceed of real profits from intermediate-goods firms (owned by households), and $\tau_{t}$ is the real tax or transfer. The consumption index $C_{t}$ is a Dixit-Stiglitz CES aggregator of differentiated consumption goods or varieties, given by

$$
C_{t}=\left[\int_{0}^{1} C_{t}(i)^{1 /\left(1+\theta_{t}\right)} d i\right]^{1+\theta_{t}}
$$

where

$$
\theta_{t}=1 /\left(\eta_{t}-1\right)
$$


is the firms' stochastic average markup at time $t$ and $\eta_{t}$ is the elasticity of substitution across varieties.

The resulting households' efficiency conditions:

$$
\begin{gathered}
0=C_{t}^{-\sigma}\left(1-N_{t}\right)^{\gamma(1-\sigma)}-\lambda_{t} \\
0=-\gamma C_{t}^{1-\sigma}\left(1-N_{t}\right)^{\gamma(1-\sigma)-1}+\lambda_{t} w_{t} \\
0=\lambda_{t}-\beta R_{t} E_{t} \frac{\lambda_{t+1}}{\Pi_{t+1}}
\end{gathered}
$$

Here, $\lambda_{t}$ is the Lagrange multiplier (the shadow cost of consumption).

\section{Firms}

Firms produce the differentiated varieties using the production function

$$
Y_{t}(i)=z_{t} N_{t}(i)
$$

The labor market is global. Firms face infrequent opportunities to adjust their prices optimally in a Calvo (1983) manner, with probability $1-\alpha$ every period. When a firm $i$ is not allowed to adjust optimally, with probability $\alpha$, it simply indexes its current prices to the constant long-run (steady-state) inflation target:

$$
P_{t}(i)=P_{t-1}(i) \bar{\Pi}
$$

Given the CES aggregation and the above structure, the demand for each variety $i$ at time $t+j$ for firms that last adjusted its price optimally at time $t$ is

$$
Y_{t+j}(i)=\left[\frac{\tilde{P}_{t} \Psi_{j t}}{P_{t+j}}\right]^{-\eta_{t}} Y_{t+j}
$$

where, given the indexation scheme,

$$
\Psi_{j t}=\bar{\Pi}^{j}
$$


$Y_{t}$ is the aggregate output and $\tilde{P}_{t}$ is the common optimal price at $t$ chosen by all optimizing firms, satisfying

$$
0=E_{t} \sum_{j=0}^{\infty} \alpha^{j} Q_{t, t+j} Y_{t+j} P_{t+j}^{\eta_{t}} \Psi_{j t}^{1-\eta_{t}}\left[\tilde{P}_{t}-\frac{\eta_{t}}{\eta_{t}-1} M C_{t+j} \Psi_{j t}^{-1}\right]
$$

$Q_{t, t+j} \equiv \beta^{j} E_{t} \frac{\lambda_{t+j} / P_{t+j}}{\lambda_{t} / P_{t}}, M C_{t}$, and $P_{t}$ denoting the nominal stochastic discount factor (between time $t$ and $t+j$ ), nominal marginal cost, and the aggregate price level, respectively.

The aggregate price level is given by

$$
P_{t}^{1-\eta_{t}}=(1-\alpha)\left(\tilde{P}_{t}\right)^{1-\eta_{t}}+\alpha\left(\bar{\Pi} P_{t-1}\right)^{1-\eta_{t}}
$$

Equating aggregate demand with aggregate supply, we obtain (after some rearranging)

$$
\begin{aligned}
& z_{t} N_{t}=Y_{t} \Delta_{t}, \\
& Y_{t}=C_{t}+G_{t},
\end{aligned}
$$

where $\Delta_{t}=\int_{0}^{1}\left(P_{t}(i) / P_{t}\right)^{-\eta_{t}} d i$ is a measure of price dispersion, i.e. the relative-price distortion. $G_{t}$ is the aggregate government spending, aggregated the same way as in (A.1).

\section{Recursive representations}

The optimal price equation (A) and the aggregate price equation (A) can be expressed recursively as

$$
\begin{gathered}
\tilde{p}_{t} \equiv \frac{\tilde{P}_{t}}{P_{t}}=\frac{\eta_{t}}{\eta_{t}-1} \frac{K_{1 t}}{K_{2 t}} \\
K_{1 t}=\lambda_{t} Y_{t} m c_{t}+E_{t}\left[\alpha \beta \bar{\Pi}^{-\eta_{t}} \Pi_{t+1}^{\eta_{t}} K_{1, t+1}\right] \\
K_{2 t}=\lambda_{t} Y_{t}+E_{t}\left[\alpha \beta \bar{\Pi}^{1-\eta_{t}} \Pi_{t+1}^{\eta_{t}-1} K_{2, t+1}\right] \\
1=(1-\alpha)\left(\tilde{p}_{t}\right)^{1-\eta_{t}}+\alpha\left(\bar{\Pi} \Pi_{t}^{-1}\right)^{1-\eta_{t}} .
\end{gathered}
$$


$m c_{t} \equiv M C_{t} / P_{t}$ is the average real marginal cost — given the production function,

$$
m c_{t}=w_{t} / z_{t}
$$

We can also recursively write the relative-price distortion as

$$
\Delta_{t}=(1-\alpha)\left(\tilde{p}_{t}\right)^{-\eta_{t}}+\alpha\left(\bar{\Pi} \Pi_{t}^{-1}\right)^{-\eta_{t}} \Delta_{t-1}
$$

\section{The monetary policy rule and the adjustment of the medium-run inflation target}

In the benchmark model without the adjustment of the medium-run inflation target (MRIT), the monetary policy authority is assumed to follow a Taylor-type rule,

$$
\log \left(R_{t} / \bar{R}\right)=\phi_{\pi} \log \left(\Pi_{t} / \bar{\Pi}\right)+\phi_{Y} \log \left(Y_{t} / Y_{t}^{*}\right)
$$

where $Y_{t}^{*}$ is the potential or natural level of output, defined as the level of output in the flexible-price equilibrium with constant markup, satisfying

$$
Y_{t}^{*}=\frac{\frac{(\bar{\eta}-1)}{\bar{\eta}} z_{t}+\gamma G_{t}}{\gamma+\frac{(\bar{\eta}-1)}{\bar{\eta}}} .
$$

In an alternative model with our proposed policy, the monetary authority employs the modified Taylor-type rule and adjusts the MRIT in response to the markup shock:

$$
\begin{aligned}
\log \left(R_{t} / \bar{R}\right) & =\phi_{\pi} \log \left(\Pi_{t} / \Pi_{t}^{*}\right)+\phi_{Y} \log \left(Y_{t} / Y_{t}^{*}\right) \\
\log \left(\Pi_{t}^{*}\right) & =\log (\bar{\Pi})+\mu_{\pi^{*}} v_{\pi^{*}, t} \\
v_{\pi^{*}, t} & =\rho_{{\pi^{*}}^{*}} v_{\pi^{*}, t-1}+\varepsilon_{\theta, t}
\end{aligned}
$$

Here, we assume that the adjustment of the MRIT is entirely endogenous, i.e. it evolves entirely due to the monetary authority's action, rather than exogenously. Setting $\mu_{\theta}=0$ yields the standard assumption that the medium-run inflation target is equal to its constant 
long-run inflation target.

\section{Evolution of exogenous variables}

The model has three exogenous variables: productivity, $z_{t}$, government spending, $G_{t}$, and average markup, $\theta_{t}$. Their evolutions follow

$$
\begin{gathered}
\log \left(z_{t}\right)=\rho_{z} \log \left(z_{t-1}\right)+\varepsilon_{z, t}, \\
\log \left(G_{t} / \bar{G}\right)=\rho_{g} \log \left(G_{t-1} / \bar{G}\right)+\varepsilon_{g, t}, \\
\log \left(\theta_{t}\right)=\left(1-\rho_{\theta}\right) \log (\bar{\theta})+\rho_{\theta} \log \left(\theta_{t-1}\right)+\varepsilon_{\theta, t} .
\end{gathered}
$$

Aggregate fluctuations are driven by three exogenous shocks: $\varepsilon_{z, t} \sim$ i.i.d. $N\left(0, \sigma_{z}^{2}\right), \varepsilon_{g, t} \sim$ i.i.d. $N\left(0, \sigma_{g}^{2}\right)$, and $\varepsilon_{\theta, t} \sim$ i.i.d. $N\left(0, \sigma_{\theta}^{2}\right)$.

\section{Complete equilibrium equations (competitive equilibrium)}

In the standard model without MRIT, the complete equilibrium conditions (under competitive equilibrium) are given by equations (A.2), (A.3), (A.4), (A.5), (A.6), (A.7), (A.8), (A.9), (A.10), (A.11), (A.12), (A.13), (A.14), (A.15), and the evolution equations of exogenous variables (A.19)- (A.21). The corresponding endogenous variables are $C_{t}, Y_{t}, N_{t}, \lambda_{t}, w_{t}, R_{t}, \Pi_{t}$, $\tilde{p}_{t}, K_{1 t}, K_{2 t}, \Delta_{t}, m c_{t}, Y_{t}^{*}$, and $\eta_{t}$

In the model with the MRIT adjustment, the policy rule (A.14) is replaced with (A.16)(A.18). The medium-run inflation target, $\Pi_{t}^{*}$, is now an endogenous variable. We solve for the equilibrium using the perturbation method, up to a second-order approximation.

\section{Ramsey policy}

We derive the Ramsey equilibrium by formulating a recursive Lagrangian as in Marcet and Marimon (2011). The objective function is the households' welfare as the Ramsey policy authority is benevolent. The Ramsey authority conducts policy in a decentralized setting. This means that all the private-sector efficiency conditions described above have to be re- 
spected, and becomes the constraint set in the optimal policy problem (the Lagrangian). As is standard in the literature, we do not take a stand on the form of the optimal policy rule and search instead for the equilibrium allocation under the Ramsey policy — in technical term, this means that policy rule (A.14) is not part of the Ramsey authority's constraint set. The Ramsey policy is solved under the assumption of a constant long-run inflation target, $\Pi_{t}^{*}=\bar{\Pi}$. 